\title{
The Impact of Endoscopic Stapler Selection on Bleeding at the Vascular Stump in Pulmonary Artery Transection
}

This article was published in the following Dove Press journal: Medical Devices: Evidence and Research

\section{Yoshio Tsunezuka Nobuhiro Tanaka (ID Hideki Fujimori}

Department of General Thoracic Surgery, Ishikawa Prefectural Central Hospital, Kanazawa, Japan
Correspondence: Yoshio Tsunezuka Department of General Thoracic Surgery, Ishikawa Prefectural Central Hospital, Kuratsukihigashi 2-I, Kanazawa 920-8530, Japan

Tel +8I-76-237-82II

$\mathrm{Fax}+8 \mathrm{I}-76-238-2337$

Email tsuney@nifty.com
Objective: To assess bleeding following transection of the pulmonary artery with powered and manual endoscopic staplers.

Methods: Cases of video-assisted and open-chest thoracic surgical procedures for non-small cell lung cancer at Ishikawa Prefectural Central Hospital were reviewed between 2012 and 2018. Three stapler groups were assessed: Group 1 - Ethicon ECHELON FLEX ${ }^{\mathrm{TM}}$ Powered Vascular Stapler (PVS), Group 2 - Medtronic Endo-GIA ${ }^{\mathrm{TM}}$ iDrive ${ }^{\mathrm{TM}}$ powered stapler, Group 3 - Ethicon and Medtronic manual staplers.

Results: Of 239 patients, 82 cases (34.3\%) were Group 1, 94 cases (39.3\%) were Group 2 and 63 cases (26.4\%) were Group 3. Mean age was 68.3 years (range 36-88 years), and most patients received video-assisted right upper lobectomy $(82.8 \%)$. Bleeding occurred in 24 cases: $17(70.8 \%)$ in Group 2 and $7(29.2 \%)$ cases in Group 3. No bleeding occurred in Group 1. The loaded ECHELON FLEX ${ }^{\mathrm{TM}}$ PVS and Endo-GIA ${ }^{\mathrm{TM}}$ iDrive $^{\mathrm{TM}}$ with gray cartridge combinations had the greatest and smallest closed anvil jaw gaps $(>0.63 \mu \mathrm{m}$ and $<0.15 \mu \mathrm{m}$, respectively); Endo-GIA ${ }^{\mathrm{TM}}$ iDrive $^{\mathrm{TM}}$ gray cartridge combinations resulted in ruptures of inner and middle membranes of the pulmonary artery. No ruptures were observed using the ECHELON FLEX ${ }^{\mathrm{TM}}$ PVS.

Conclusion: An excessively narrow gap between cartridge and anvil may damage the blood vessel wall and lead to bleeding following transection. This study provides preliminary evidence that the use of the ECHELON FLEX ${ }^{\mathrm{TM}}$ PVS and tan cartridges for pulmonary artery stapling may help to prevent tissue damage and intraoperative bleeding.

Keywords: surgery, stapler, pulmonary artery, bleeding

\section{Introduction}

Endoscopic staplers are crucial tools for thoracoscopic surgical procedures: however, stapling of pulmonary vasculatures during thoracic surgery can be associated with intraoperative adverse events, such as bleeding from transected tissue. ${ }^{1}$ Additionally, leaking or oozing of blood from arterial stumps may obscure the surgical area and causes stress to surgeons. ${ }^{2}$

Powered staplers incorporate a motor to power both staple firing and the cutting action of the blade. By reducing movement at the distal tip up to $88 \%$ versus manual staplers, powered staplers minimize the impact of surgeons' hand tremors during firing; 3,4 this reduces trauma to adjacent tissue and potential instances of bleeding. Expert consensus regarding endoscopic stapling in thoracic surgery is that improved device stability could reduce surgeons' stress and prevent unintentional 
tissue damage during surgery. ${ }^{5}$ Recent research has demonstrated evidence of potential clinical (bleeding and transfusion) and economic benefits associated with the use of powered staplers compared to manual staplers in videoassisted thoracoscopic surgery (VATS) lobectomies. ${ }^{4}$ However, no comparison between outcomes associated with the use of differently powered staplers has been reported to date.

Anecdotal evidence from discussions with experienced surgeons suggests differences in bleeding levels between different powered devices. This case series assessed bleeding at the arterial stump following transection of the pulmonary artery during VATS and open-chest surgical procedures for lung cancer. The characteristics and performance of different endoscopic staplers, powered and manual, were evaluated.

\section{Materials and Methods}

\section{Study Design, Procedures and Evaluations}

Endoscopic stapler use during VATS and open surgery for non-small cell lung cancer, focusing on the right apicalanterior (RA) truncus of the pulmonary artery, was reviewed retrospectively in consecutive patients at Ishikawa Prefectural Central Hospital between January 2012 and December 2018. Demographic and clinical data were collected. All cases were first lung resection; no prior chemotherapy nor radiotherapy was conducted. Patients were followed up in the same center. All surgeons performing the procedures were members of the Japanese Board of General Thoracic Surgeons and all surgical cases were performed under consultation of supervisor surgeons. All results presented in this article are in aggregate form, and no personally identifiable information was used for this study.

\section{Inclusion Criteria}

Single right upper lobectomy, lobectomy with $>2$ lobes including the right upper lobe, and cases of bronchoplasty and/or right upper lobectomy with combined resection of the chest wall.

\section{Exclusion Criteria}

Patients with diabetes, pyothorax, and/or steroid intake (due to the potential vulnerability of the pulmonary artery), patients on anti-coagulation medicines (due to increased hemorrhagic tendency), and patients with recurrent cancer, induction chemotherapy and/or chemoradiotherapy. Robotassisted cases and cases in which obvious technical issues had occurred were also excluded.

\section{Total Thoracoscopic Right Upper Lobectomy Procedure}

After a double-lumen endotracheal intubation, patients were positioned in a left lateral position under general anesthesia. A 30-degree thoracoscope was inserted through the seventh intercostal port at the mid-axillary line. A lateral skin incision (approximately $2-3 \mathrm{~cm}$ ) was made as a window, generally by performing a fourth intercostal thoracotomy from the mid-axillary line. The Wound Protector (SurgiSleeve ${ }^{\mathrm{TM}}$, extra small size, Medtronic, USA) was placed through the window. Generally, pulmonary arteries (diameter $>10 \mathrm{~mm}$ ) were divided with staplers, thick pulmonary arteries $\geq 5 \mathrm{~mm}$ in diameter were ligated with $1-0$ sutures and the peripheral site was ligated with an energy sealing device. Arteries $<5 \mathrm{~mm}$ in diameter were ligated with the energy sealing device only. The RA truncus was divided by a stapler through the seventh intercostal port at the mid-axillary line. In all cases of open thoracotomy, a scope was used as a light source and to record the procedure.

During stapling, vessels were held gently, and the stapler shaft was rested on the chest-wall port to minimize hand shaking while firing. Stapling was conducted according to Shimizu et al (2018), to avoid possible situations that could lead to vascular dissection. ${ }^{6}$ Stapler placement, assessment of tension and firing of staplers were monitored using the surgical video-assisted system. To minimize bias, surgeries were reviewed from a single center and performed by six experienced thoracic surgeons certified by the Japanese Board of General Thoracic Surgery.

\section{Evaluation of Stapler Devices}

Patients were divided into three stapler groups: Group 1 Ethicon's ECHELON FLEX ${ }^{\mathrm{TM}}$ powered vascular stapler (PVS), Group 2 - Medtronic's powered Endo-GIA ${ }^{\mathrm{TM}}$ iDrive $^{\mathrm{TM}}$ stapler (using white, gray and tan cartridges); and Group 3 - Endo-GIA ${ }^{\mathrm{TM}}$ Universal (using white, gray and tan cartridges) and ECHELON FLEX ${ }^{\mathrm{TM}}$ ENDOPATH $^{\circledR}$ (using white cartridges only) manual staplers (Table 1).

Staple characteristics including leg length, crown length, height (closed), diameter, and pitch width were measured. Differences in closed anvil jaw gap after loading with different staple cartridges were determined by inserting paper sheets of $106 \mu \mathrm{m}$ thickness into the space. Anvil jaw angle was measured using a protractor. 
Table I Evaluation of Intraoperative Bleeding After Endoscopic Stapler Use in Pulmonary Artery Transection

\begin{tabular}{|c|c|c|c|}
\hline $\mathrm{p}$ value $<0.000 \mathrm{I}^{\mathrm{a}}$ & $\begin{array}{l}\text { Patients } \\
\text { n (\%) } \\
N=239\end{array}$ & $\begin{array}{l}\text { Bleeding } \\
\text { Cases }^{b} \text { n (\%) } \\
N=24\end{array}$ & $\begin{array}{l}\text { Closed } \\
\text { Anvil Jaw } \\
\text { Space, } \mu \mathrm{m}\end{array}$ \\
\hline $\begin{array}{l}\text { Group I: ECHELON FLEX }{ }^{\mathrm{TM}} \text { PVS (PVE35A) } \\
\text { ECHELON ENDOPATH }{ }^{\mathrm{TM}} 35 \mathrm{~mm} \text { Vascular Reloads (VASECR35) }\end{array}$ & $\begin{array}{l}82(34.3) \\
82(34.3)\end{array}$ & $\begin{array}{l}0(0.0) \\
0(0.0)\end{array}$ & - \\
\hline $\begin{array}{l}\text { Group 2: Endo-GIA }{ }^{\mathrm{TM}} \text { iDrive }{ }^{\mathrm{TM}} \text { Ultra Powered Handle I (IDRVULTRAI) } \\
\text { Gray cartridge (Endo-GIA }{ }^{\mathrm{TM}} 45 \mathrm{~mm} \text { Curved Tip Articulating Vascular Reload [EGIA45CTAV]) } \\
\text { White cartridge (Endo-GIA-II white cartridge 45) } \\
\text { Tan cartridge (Endo-GIA }{ }^{\mathrm{TM}} 45 \mathrm{~mm} \text { Curved Tip Articulating Vascular/Medium Reload with Tri-Staple }{ }^{\mathrm{TM}} \\
\text { Technology [EGIA45]) }\end{array}$ & $\begin{array}{l}94(39.3) \\
61(25.5) \\
4(1.7) \\
29(12.1)\end{array}$ & $\begin{array}{l}17(70.8) \\
15(62.5) \\
2(8.3) \\
0(0.0)\end{array}$ & $\begin{array}{l}- \\
0.106 \\
0.212 \\
0.530\end{array}$ \\
\hline $\begin{array}{l}\text { Group 3: Endo-GIA }{ }^{\mathrm{TM}} \text { Ultra Universal Stapler XL (EGIAUXL)/ECHELON FLEX }{ }^{\mathrm{TM}} \\
\text { ENDOPATH }^{\circledR}\end{array}$ & $63(26.4)$ & $7(29.2)$ & - \\
\hline $\begin{array}{l}\text { Endo-GIA }{ }^{\mathrm{TM}} \text { Ultra Universal Stapler XL (EGIAUXL) - gray cartridge (Endo-GIA }{ }^{\mathrm{TM}} 45 \mathrm{~mm} \\
\text { Curved Tip Articulating Vascular Reload [EGIA45CTAV]) }\end{array}$ & $25(10.5)$ & $4(16.7)$ & 0.424 \\
\hline $\begin{array}{l}\text { Endo-GIA }{ }^{\mathrm{TM}} \text { Ultra Universal Stapler XL (EGIAUXL) - white cartridge (Endo-GIA-II white cartridge } \\
\text { 45) }\end{array}$ & $8(3.3)$ & $2(8.3)$ & 0.212 \\
\hline $\begin{array}{l}\text { Endo-GIA }{ }^{\mathrm{TM}} \text { Ultra Universal Stapler XL (EGIAUXL) - tan cartridge (Endo-GIA }{ }^{\mathrm{TM}} 45 \mathrm{~mm} \text { Curved } \\
\text { Tip Articulating Vascular/Medium Reload with Tri-Staple }{ }^{\mathrm{TM}} \text { Technology [EGIA45CTAVM]) }\end{array}$ & $17(7.1)$ & $0(0.0)$ & 0.530 \\
\hline ECHELON FLEX ${ }^{\text {TM }}$ ENDOPATH ${ }^{\circledR}$ - white cartridge (Endoscopic Linear Cutter Reloads [ECR45W]) & $13(5.4)$ & $\mathrm{I}(4.2)$ & 0.212 \\
\hline
\end{tabular}

Notes: ${ }^{a}$ Fisher Exact test. ${ }^{b} 2$ bleeding cases were from thoracotomy, 10 bleeding cases were from video-assisted thoracoscopic surgery. Groups 1 and 2 are powered staplers, Group 3 are manual staplers. ECHELON staplers are manufactured by Ethicon, Endo-GIA ${ }^{\text {TM }}$ staplers are manufactured by Medtronic.

\section{Evaluation of Intraoperative Oozing/ Bleeding}

Post stapling oozing/bleeding, defined as bleeding that continues after application of pressure for $10 \mathrm{~s}$, was assessed for all staplers and stapler cartridges. When bleeding was observed from the pulmonary artery resection stump, a gauze was applied and compressed for $10 \mathrm{~s}$; if hemostasis was achieved cases were categorized as no-bleeding. Cases with continued bleeding after $10 \mathrm{~s}$ ' compression were classified as oozing/bleeding events. In such cases, further compression, the use of a soft-coagulation device, or sutures were used to achieve complete hemostasis.

\section{Histology}

Histology was performed on the truncus superior transected by the Endo-GIA ${ }^{\mathrm{TM}}$ iDrive $^{\mathrm{TM}}$ loaded with gray cartridges, and the ECHELON FLEX ${ }^{\mathrm{TM}}$ PVS. Stapled, resected, right-upper lobe tissue was excised with a scalpel and the morphology of the tunica intima and media was observed. Histological sections were stained with Elastica van Gieson (EVG) stain w10x, coloring elastic fiber black and purple, and collagen fiber pink.

\section{Statistical Analyses}

Any association between stapler/cartridge type and bleeding events was assessed using a Fisher's exact test.

\section{Ethics}

All procedures performed in this study were in accordance with the ethical standards of the Ishikawa Prefectural Central Hospital Institutional Review Board and with the 1964 Helsinki Declaration and its later amendments. Informed consent was not required as all patient data were fully anonymized and patient data confidentiality was maintained at all times.

\section{Results}

\section{Patient Characteristics}

From January 2012 to December 2018, 1139 patients with primary lung cancer were operated on and 250 RATs were intraoperatively incised. Among them, 5 RA trunci were ligated with suture materials, and 6 cases were operated with the da Vinci ${ }^{\circledR}$ Surgical System - those 11 cases were excluded resulting in a total of 239 RA trunci cases that were divided with staplers.

There were $82(34.3 \%)$ cases in stapler Group 1, 94 (39.3\%) in Group 2, and 63 (26.4\%) in Group 3. Most patients received a VATS right upper lobectomy. Baseline demographics, except for gender, were balanced between the Groups; more patients in Group 1 (ECHELON FLEX $^{\mathrm{TM}}$ PVS group) were male $(91.5 \%)$ compared to Groups 2 (53.2\%) and 3 (60.3\%) (Supplementary Table 1). 


\section{Intraoperative Bleeding}

Overall, bleeding after stapling occurred in 24/239 (10.0\%) cases; most occurred in Group 2 (Endo-GIA $^{\mathrm{TM}}$ iDrive $^{\mathrm{TM}}$; 17/24 [70.8\%]): 15/61 (24.6\%) and 2/4 (50\%) bleeding events were observed for gray and white cartridges, respectively. In Group 3 (manual staplers) there were 7/24 (29.2\%) bleeding cases: $4 / 25$ and $2 / 8$ for Endo-GIA ${ }^{\mathrm{TM}}$ Universal with gray and white cartridges, respectively, and $1 / 13$ for the ECHELON FLEX ${ }^{\mathrm{TM}}$ ENDOPATH $^{\circledR}$ with white cartridge. No incidences of bleeding were observed in Group 1 (ECHELON FLEX ${ }^{\mathrm{TM}}$ PVS; Table 1) or Groups 2 and 3 when using the tan cartridges. Of the 24 bleeding cases, 9 were male, 9 were smokers, 17 had adenocarcinoma, and 7 had squamous cell carcinoma. The results from the Fisher's exact test ( $<<0.0001$, unadjusted) suggest that bleeding events and stapler/cartridge type are not independent, ie, there is an association between stapler/cartridge type and whether a bleeding event occurs. The location of the tumor (peripheral versus central) and the presence of metastases were not found to associate with bleeding.

No bleeding cases required suturing. Most bleeding originated from the pulmonary artery resection stump of the resected lungs (after transecting the pulmonary veins); $2 / 24$ cases $(8.3 \%)$ of bleeding from the proximal stump were observed. Fourteen cases used a soft-coagulation device and achieved hemostasis. No cases required reintervention and no cases of delayed bleeding were observed.

\section{Staple and Stapler Characteristics}

Staple measurements were similar for the ECHELON FLEX $^{\mathrm{TM}}$ PVS, the manual ECHELON FLEX ${ }^{\mathrm{TM}}$ ENDO $\mathrm{PATH}^{\circledR}$ stapler (white cartridge), and the powered EndoGIA $^{\mathrm{TM}}$ iDrive $^{\mathrm{TM}}$ stapler (gray cartridge). Staple cartridges differed in number of staples used and pitch width (Supplementary Table 2).

The open anvil jaw gaps of the ECHELON FLEX ${ }^{\mathrm{TM}}$ PVS and the Endo-GIA ${ }^{\mathrm{TM}}$ staplers were both approximately 15 degrees (Figure 1A and B). When the anvil jaws were closed, the loaded ECHELON FLEX ${ }^{\mathrm{TM}}$ PVS had the greatest anvil jaw gap. The Endo-GIA ${ }^{\mathrm{TM}}$ iDrive $^{\mathrm{TM}}$ loaded with a gray cartridge had the smallest gap $(<0.15 \mu \mathrm{m}$; Table 1$)$.

\section{Histology}

Ruptures were observed in the tunica media and intima in histological sections from pulmonary artery stapling cases using the Endo-GIA ${ }^{\mathrm{TM}}$ iDrive $^{\mathrm{TM}}$ loaded with gray cartridges $(n=5)$, whereas no ruptures of the pulmonary artery wall were observed from cases using the ECHELON FLEX $^{\mathrm{TM}}$ PVS ( $\mathrm{n}=5$; Figure 1C).

\section{Discussion}

We investigated differences among powered and manual endoscopic staplers and staple characteristics to understand their impact on bleeding after stapling of the pulmonary artery during lung cancer surgery.

Bleeding at the vascular stump was most often observed in cases using the Endo-GIA ${ }^{\mathrm{TM}}$ iDrive $^{\mathrm{TM}}$ stapler followed by cases using manual staplers. No bleeding was observed in cases using the ECHELON FLEX ${ }^{\mathrm{TM}}$ PVS or when using tan cartridges, suggesting there may be a relationship between bleeding and the closed anvil jaw space, whereby a larger space $(>0.500 \mu \mathrm{m})$ leads to reduced bleeding. We found a greater number of male patients received surgical procedures involving powered staplers (Group 1) versus manual staplers (Group 3), indicating that gender may be a factor driving stapler and cartridge choice. Smoking has been shown to correlate with arterial wall stiffness and so may impact arterial wall integrity during surgery, which could potentially contribute to bleeding. ${ }^{6,7}$ In this study, Brinkman's index differed between groups; however, scores did not correlate with bleeding and so it was unlikely that differences in patient smoking histories significantly biased the findings of this study. The mean age of patients in all stapler groups was comparable (68-69 years); therefore, as the physical properties of pulmonary vessels are known to change with age, ${ }^{8}$ our results may best inform surgeries for this patient demographic.

Powered endoscopic staplers reportedly lead to fewer bleeding events during pulmonary vessel transection than manual endoscopic staplers due to increased stability during firing. ${ }^{3,4}$ Miller et al also found that powered staplers demonstrate superior results in reduced total hospital length of stay and total hospital cost in addition to bleeding management; however, this study was limited by differences in patient characteristics and different approaches in multiple centers and/or surgeons' experience, making it difficult to draw clear conclusions about the full benefits of powered versus manual staplers. ${ }^{4}$ Our results, from a single center, demonstrate that tremors during firing may not be the leading cause of bleeding during vessel transection. Differences in bleeding after stapling did not appear to be due to variation in staple characteristics or stapler anvil jaw angle, but rather loaded and closed anvil jaw gap; the closed anvil jaw gap for the loaded Endo-GIA ${ }^{\mathrm{TM}}$ iDrive $^{\mathrm{TM}}$ stapler plus gray cartridge was 


\section{Endo-GIA $^{\mathrm{TM}}$ iDrive $^{\mathrm{TM}}$}
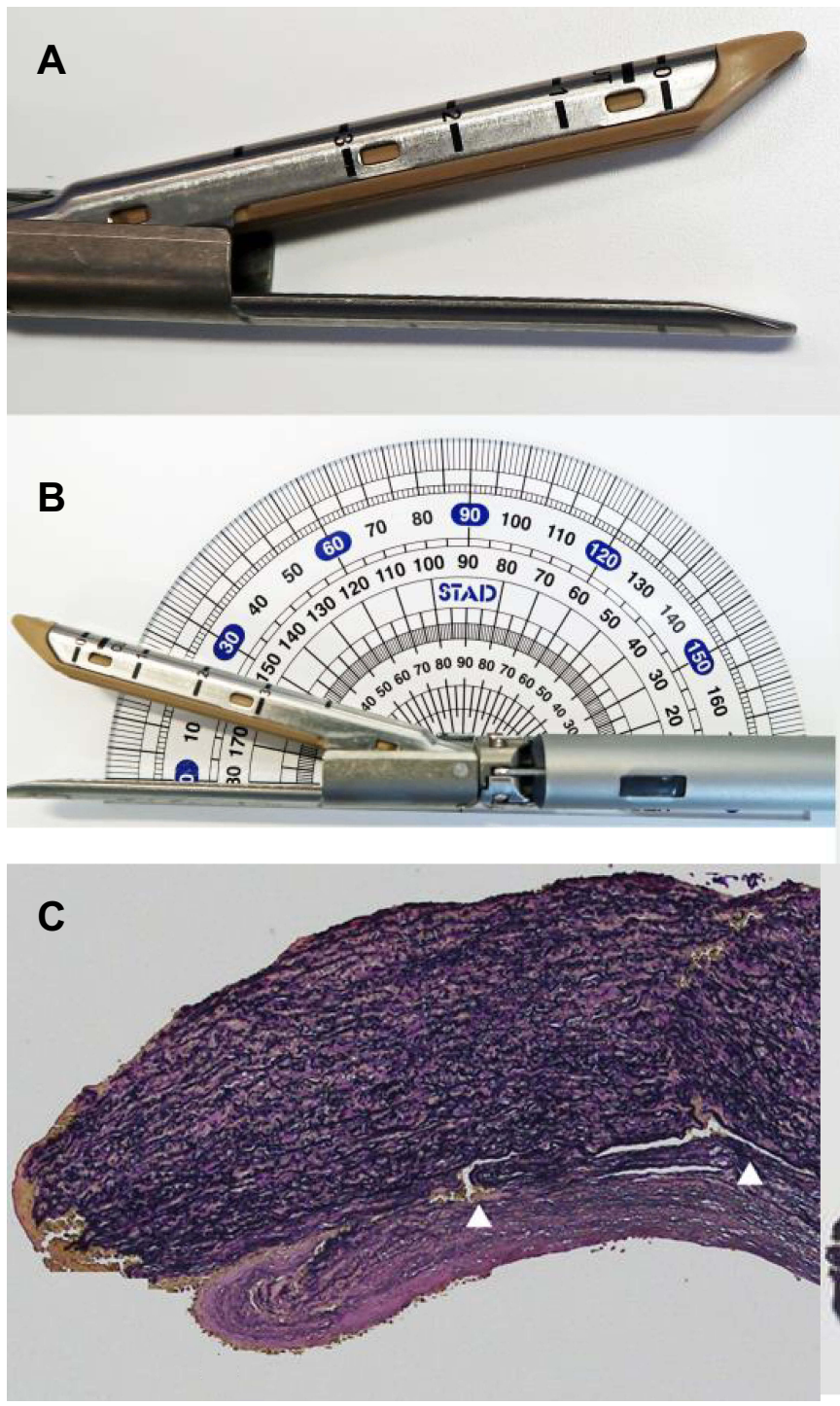

\section{ECHELON FLEX ${ }^{\mathrm{TM}}$ PVS}
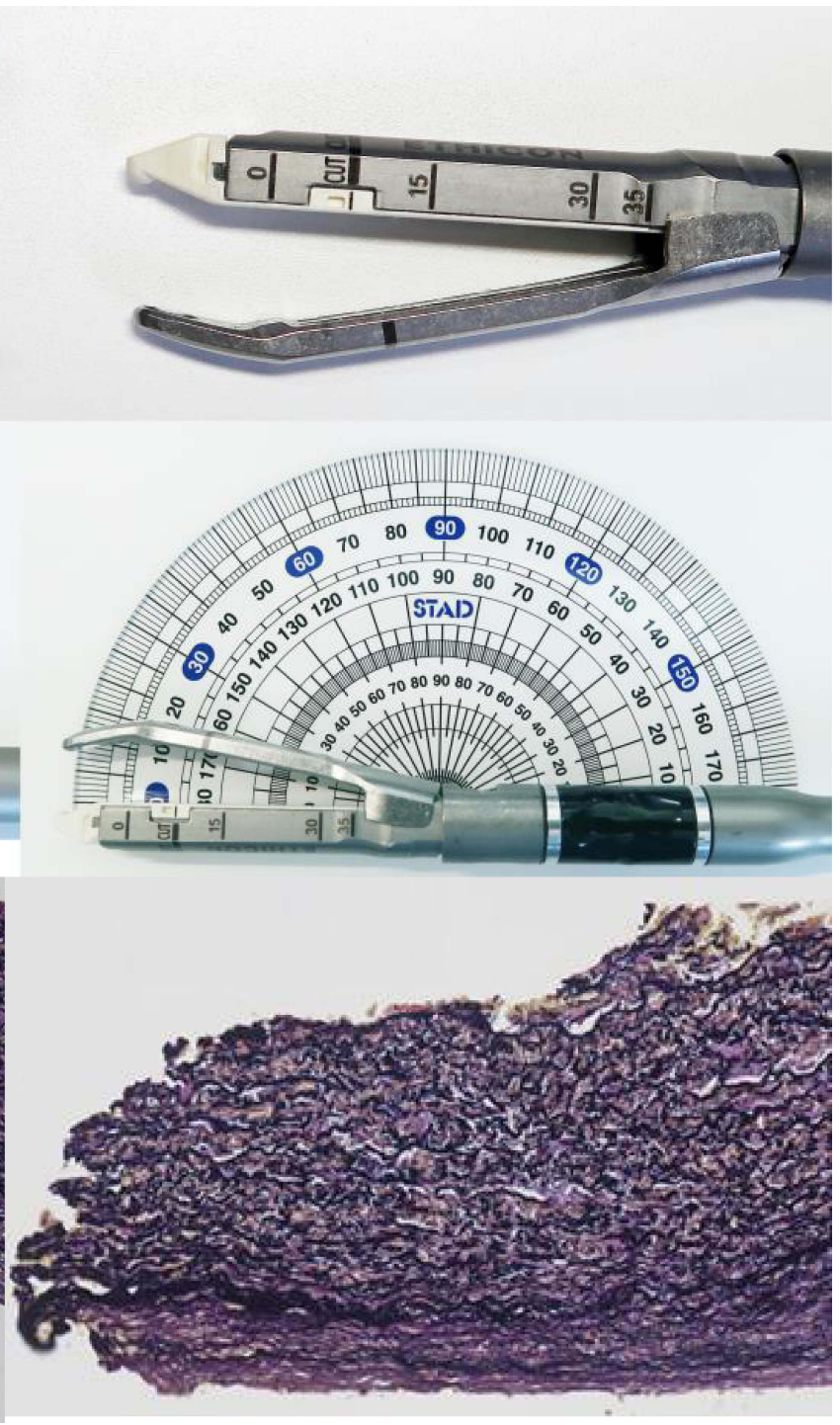

Figure I (A) Comparison of powered endoscopic staplers (B) comparison of jaw angles and (C) histological findings after pulmonary arterial stapling. Histological sections of pulmonary artery tissue adjacent to the area of stapling were stained with Elastica van Gieson stain (X200). In (C) the pulmonary artery section is from stapling with the Endo-GIA ${ }^{\mathrm{TM}}$ iDrive ${ }^{\mathrm{TM}}$ plus gray cartridge. White arrows indicate the ruptured medial layer.

Abbreviation: PVS, powered vascular stapler.

up to six times smaller than that of the loaded ECHELON FLEX $^{\mathrm{TM}}$ PVS. Additionally, histological sectioning revealed that the integrity of the inner and middle arterial wall membranes was maintained after stapling with the ECHELON FLEX $^{\mathrm{TM}}$ PVS. However, damage to the arterial wall membranes was observed in pulmonary artery sections stapled with the Endo-GIA ${ }^{\mathrm{TM}}$ iDrive $^{\mathrm{TM}}$ plus gray cartridge. Therefore, a smaller closed anvil jaw gap may confer excessive force when stapling the pulmonary artery.

For optimal tissue stapling, factors such as appropriate application of compression and the tissue's mechanical properties, including tissue quality and thickness are important to consider. ${ }^{9}$ A review of staple firings in VATS determined $7.8 \%$ of cases resulted in a minor or major problem, which may be a higher incidence versus open thoracic surgery. ${ }^{10}$ To prevent oozing and other intraoperative adverse events during VATS it is important to select an appropriate stapler and staple type. Results from a real-world study on laparoscopic bariatric surgery found ECHELON powered staplers were associated with a $47 \%$ lower rate of bleeding complications versus Medtronic Endo-GIA ${ }^{\mathrm{TM}}$ with Tri-Staple ${ }^{\mathrm{TM}}$ Technology and other manual staplers. ${ }^{3}$ Additionally, in vivo experiments in a gastrointestinal porcine model reported 
different stapler cartridge characteristics on mucosal capture, specifically that mucosal capture is associated with fluid leakage pressure. Historically, it has been considered that low cartridge height gives staple lines a tighter hold; however, it was demonstrated that inadequate cartridge height (ie, too low) for the targeted tissue/organ insufficiently captures intimal tissue. Although not tested clinically, it has been concluded that the ECHELON FLEX ${ }^{\mathrm{TM}}$ GST with GST 60G cartridge is best suited for gastrointestinal stapling. ${ }^{11}$ In our study, we focused on vessel wall damage associated with anvil jaw gap. The pathology results demonstrated damage to the artery intimal tissues around the staples if an inadequate choice of stapler cartridge was made. Therefore, although the stapler mechanism (ie, powered or manual) is an important factor for bleeding management in vessel transection, the loaded anvil jaw gap also influences vessel-wall tissue damage. From this point of view, the ECHELON FLEX ${ }^{\mathrm{TM}}$ PVS is considered effective for pulmonary artery transection.

\section{Limitations}

A limitation of this study was that only cases of surgery on the right upper lobe of the pulmonary artery and superior trunk were reviewed; further investigations between patients who have different tumor locations and stages are required. Unaccounted for patient-specific differences (eg, thickness of the pulmonary arterial wall, pulmonary arterial pressure, patient's smoking status, or use of anticoagulant medications) may also have influenced the results. Additionally, variation in skills between different surgeons could also influence bleeding after stapling; however, there was no association between surgeon experience and bleeding. Finally, although the study demonstrates differences between devices, the magnitude of these differences and clinical impact are difficult to ascertain using a retrospective study design and so further studies are needed.

\section{Conclusions}

Membrane damage can lead to bleeding following transection and may be attributable to the endoscopic stapler and staple type used. This study provides preliminary evidence that the use of the ECHELON FLEX ${ }^{\mathrm{TM}}$ PVS or tan cartridges for pulmonary artery stapling may help to prevent tissue damage, potentially reducing intraoperative stress and surgical complications associated with unexpected bleeding.

\section{Acknowledgments}

The authors acknowledge Ruth Le Fevre, PhD, Costello Medical Singapore Pte Ltd, Singapore, and Simon Foulcer, $\mathrm{PhD}$, Costello Medical, UK, for writing and editorial assistance. All costs associated with development of this article were funded by Medical Device Business Services Inc.

\section{Author Contributions}

All authors made substantial contributions to conception and design, acquisition of data or analysis and interpretation of data; took part in drafting the article or revising it critically for important intellectual content; gave final approval of the version to be published; and agree to be accountable for all aspects of the work.

\section{Funding}

Third-party writing assistance for this article, provided by Ruth Le Fevre, PhD, Costello Medical, Singapore, and Simon Foulcer, PhD, Costello Medical, UK, was funded by Medical Device Business Services Inc.

\section{Disclosure}

The authors report no conflicts of interest in this work.

\section{References}

1. Yano M, Takao M, Fujinaga T, et al. Adverse events of pulmonary vascular stapling in thoracic surgery. Interact Cardiovasc Thorac Surg. 2013;17(2):280-284. doi:10.1093/icvts/ivt130

2. Wetzel CM, Kneebone RL, Woloshynowych M, et al. The effects of stress on surgical performance. Am J Surg. 2006;191(1):5-10. doi:10.1016/j.amjsurg.2005.08.034

3. Roy S, Yoo A, Yadalam S, Fegelman EJ, Kalsekar I, Johnston SS. Comparison of economic and clinical outcomes between patients undergoing laparoscopic bariatric surgery with powered versus manual endoscopic surgical staplers. J Med Econ. 2017;20(4):423-433. doi:10.1080/13696998.2017.1296453

4. Miller DL, Roy S, Kassis ES, Yadalam S, Ramisetti S, Johnston SS. Impact of powered and tissue-specific endoscopic stapling technology on clinical and economic outcomes of video-assisted thoracic surgery lobectomy procedures: a retrospective, observational study. Adv Ther. 2018;35(5):707-723. doi:10.1007/s12325-018-0679-z

5. Miller D, Gonzalez Rivas D, Meyer K, Clark RS, Kohno T. The impact of endoscopic linear stapling device stability in thoracic surgery: a delphi panel approach. Value Health. 2015;18(3):A213. doi:10.1016/j.jval.2015.03.1236

6. Shimizu N, Tanaka Y, Okamoto T, Doi T, Hokka D, Maniwa Y. How to prevent adverse events of vascular stapling in thoracic surgery: recommendations based on a clinical and experimental study. J Thorac Dis. 2018;10(12):6466-6471.

7. Hata K, Nakagawa T, Mizuno M, et al. Relationship between smoking and a new index of arterial stiffness, the cardio-ankle vascular index, in male workers: a cross-sectional study. Tob Induc Dis. 2012;10:11. doi:10.1186/1617-9625-10-11 
8. Mackay EH, Banks J, Sykes B, Lee G. Structural basis for the changing physical properties of human pulmonary vessels with age. Thorax. 1978;33(3):335-344. doi:10.1136/thx.33.3.335

9. Pickens A Endoscopic thoracic surgery for lung cancer: mastering tools to optimize patient outcomes. General Surgery News. 2011 Available from: https://www.generalsurgerynews.com/download/ BB1134_SOTM_gsn_WM.pdf. Accessed 2018 August.
10. Gossot D, Merlusca G, Tudor A, Boudaya MS, Radu C, Magdeleinat P. Pitfalls related to the use of endostaplers during video-assisted thoracic surgery. Surg Endosc. 2009;23(1):189-192. doi:10.1007/s00464-008-9765-7

11. Thompson SE, Young MT, Lewis MT, et al. Initial assessment of mucosal capture and leak pressure after gastrointestinal stapling in a porcine model. Obes Surg. 2018;28(11):3446-3453. doi:10.1007/s11695-018-3363-0

\section{Publish your work in this journal}

Medical Devices: Evidence and Research is an international, peerreviewed, open access journal that focuses on the evidence, technology, research, and expert opinion supporting the use and application of medical devices in the diagnosis, monitoring, treatment and management of clinical conditions and physiological processes. The identification of novel devices and optimal use of existing devices which will lead to improved clinical outcomes and more effective patient management and safety is a key feature of the journal. The manuscript management system is completely online and includes a very quick and fair peer-review system. Visit http:// www.dovepress.com/testimonials.php to read real quotes from published authors. 